\title{
Red Eye
}

National Cancer Institute

\section{Source}

National Cancer Institute. Red Eye. NCI Thesaurus. Code C50725.

Lay term applied to any condition with dilation of conjunctival or ciliary blood vessels;

innumerable causes, especially irritation and infection. 